\title{
Nanocomposite Coatings Codeposited with Nanoparticles Using Aerosol-Assisted Chemical Vapour Deposition
}

\author{
Xianghui Hou, ${ }^{1}$ Kwang-Leong Choy, ${ }^{1}$ Nathalie Brun, ${ }^{2}$ and Virginie Serín ${ }^{3}$ \\ ${ }^{1}$ Faculty of Engineering, Energy and Sustainability Research Division, The University of Nottingham, Nottingham NG7 2RD, UK \\ ${ }^{2}$ Laboratoire de Physique des Solides, Université Paris-Sud, CNRS, UMR 8502, 91405 Orsay Cedex, France \\ ${ }^{3}$ CEMES Université Paul Sabatier, 29 rue Jeanne Marvig, BP 94347, 31055 Toulouse Cedex 4, France
}

Correspondence should be addressed to Kwang-Leong Choy; kwang-leong.choy@nottingham.ac.uk

Received 6 April 2013; Accepted 7 May 2013

Academic Editor: Jiamin Wu

Copyright (c) 2013 Xianghui Hou et al. This is an open access article distributed under the Creative Commons Attribution License, which permits unrestricted use, distribution, and reproduction in any medium, provided the original work is properly cited.

\begin{abstract}
Incorporating nanoscale materials into suitable matrices is an effective route to produce nanocomposites with unique properties for practical applications. Due to the flexibility in precursor atomization and delivery, aerosol-assisted chemical vapour deposition (AACVD) process is a promising way to synthesize desired nanocomposite coatings incorporating with preformed nanoscale materials. The presence of nanoscale materials in AACVD process would significantly influence deposition mechanism and thus affect microstructure and properties of the nanocomposites. In the present work, inorganic fullerene-like tungsten disulfide $\left(\right.$ IF-WS $S_{2}$ ) has been codeposited with $\mathrm{Cr}_{2} \mathrm{O}_{3}$ coatings using AACVD. In order to understand the codeposition process for the nanocomposite coatings, chemical reactions of the precursor and the deposition mechanism have been studied. The correlation between microstructure of the nanocomposite coatings and the codeposition mechanism in the AACVD process has been investigated. The heterogeneous reaction on the surface of IF-WS 2 nanoparticles, before reaching the substrate surface, is the key feature of the codeposition in the AACVD process. The agglomeration of nanoparticles in the nanocomposite coatings is also discussed.
\end{abstract}

\section{Introduction}

Nanotechnology is one of the most popular research areas in the last decade. Materials on nanoscale can exhibit unique properties as compared to those on a macroscale [1]. Various nanoscale materials have been developed, such as nanoparticles, nanotubes, nanofibers, nanowires, nanorods, nanobelts, and nanosheets, for promising applications in semiconductors, optics, mechanics, energy, catalysts, sensors and biology, and so forth [2-7]. Incorporating these nanoscale materials into suitable matrices to form nanocomposites, either in the form of bulk materials or coatings, is considered an important route to realise the unique properties of nanoscale materials for practical applications $[8,9]$. However, nanoscale materials tend to be structurally sensitive and may lose their original properties during the incorporation into matrices to produce nanocomposites. Most studies on the use of nanoscale materials in nanocomposites or nanocomposite coatings are limited to inorganic filler and polymer matrix systems $[10,11]$, in which the processing conditions are relatively mild in order to preserve the unique microstructures and properties of the nanoscale materials. It is a challenge to produce inorganic nanocomposite systems with the incorporation of the preformed nanoscale materials into ceramic matrices, due to a much higher processing temperature and critical processing environment which tend to be less favourable for the nanoscale materials.

Inorganic fullerene-like tungsten disulfide $\left(\mathrm{IF}^{-} \mathrm{WS}_{2}\right)$ nanoparticles are excellent solid lubricants under severe conditions [12]. It is reported that incorporation of IF-WS nanoparticles into coatings would offer considerable improvements on tribological performance $[13,14]$ and adjust hydrophobic/hydrophilic behavior of the coating surface [15]. Recently, aerosol-assisted chemical vapor deposition (AACVD) has been adapted to synthesize inorganic nanocomposite coatings from the dispersion or colloid of nanoparticles $[16,17]$. We have also incorporated IF-WS ${ }_{2}$ nanoparticles into $\mathrm{Cr}_{2} \mathrm{O}_{3}$ coating using AACVD [18]. The atomization 
of precursor dispersion or colloid in AACVD process allows the introduction of preformed nanoscale materials and codeposits them with matrix materials simultaneously, to form the desired nanocomposite coatings onto the substrate surface. These results demonstrated that AACVD is a promising method for the synthesis of nanocomposite coatings with the codeposition of preformed nanoscale materials. However, the codeposition mechanism in AACVD has yet to be investigated. The presence of the nanoparticles in the precursor aerosol would influence the chemical reactions and deposition process, and hence the microstructure of the nanocomposite coatings. The codeposition has significantly deviated from a standard CVD. For better understanding of the process, it is proposed to study the codeposition mechanism in AACVD and its correlation with the microstructure of the nanocomposite coatings. The results and conclusions may also be extended to other nanocomposite coating systems, consisting of other kinds of nanoscale materials and matrices.

\section{Experimental}

Chromium nitrate nonahydrate (Aldrich) was used as chemical precursor for the deposition of chromium oxide $\left(\mathrm{Cr}_{2} \mathrm{O}_{3}\right)$, while IF-WS ${ }_{2}$ nanoparticles ranging from 80 to $220 \mathrm{~nm}$ were supplied by NanoMaterials Ltd. The basic precursor solution was prepared by dissolving chromium nitrate nonahydrate in ethanol-based solvent to form $0.05 \mathrm{M}$ solution. Then IF-WS nanoparticles were added into the basic precursor solution $(0.23 \mathrm{~g} / \mathrm{L})$ to obtain uniform suspension via an ultrasonic bath. Silicon wafers and stainless steel plates were used as substrates and cleaned in an ultrasonic bath with alcohol prior to the deposition.

The precursor suspension containing IF-WS ${ }_{2}$ nanoparticles was then atomized to generate fine aerosol droplets using an ultrasonic generator, at a frequency of $1.7 \mathrm{MHz}$, with nitrogen as carrier gas. The droplets were subsequently directed towards a heated zone where they underwent evaporation, decomposition, and chemical reactions and deposited chromium oxide coatings with IF-WS ${ }_{2}$ onto the substrates. The deposition temperatures were set in the range of 280$300^{\circ} \mathrm{C}$. Post heat-treatment of the samples was carried out to obtain crystalline $\mathrm{Cr}_{2} \mathrm{O}_{3}$ and the desired microstructure of the nanocomposite coatings. The as-deposited coatings were annealed at $500^{\circ} \mathrm{C}$ in argon for 1 hour. For comparison, pure $\mathrm{Cr}_{2} \mathrm{O}_{3}$ coatings were also synthesized from precursor solution without adding IF-WS ${ }_{2}$ nanoparticles. In order to study the intermediate reactions of the precursor in the deposition, dried precursor powder was prepared by removing the solvent from the precursor suspension at $50^{\circ} \mathrm{C}$ for 48 hours. The thermal decomposition behaviours of chromium nitrate nonahydrate and the dried precursor powder were determined separately by differential thermal analysis (DTA) using a Setaram Labsys 1600 , from $30^{\circ} \mathrm{C}$ to $700^{\circ} \mathrm{C}$, at $5^{\circ} \mathrm{C} / \mathrm{min}$ in air. The structural changes of the dried precursor powder were also investigated by a Perkin Elmer Spectrum One Fourier transform infrared spectrometer (FTIR, attenuated total reflectance mode (ATR)).
The IF-WS ${ }_{2} / \mathrm{Cr}_{2} \mathrm{O}_{3}$ coatings were characterized using a combination of scanning electron microscopy (SEM), X-ray photoelectron spectroscopy (XPS), atomic force microscope (AFM), transmission electron microscopy (TEM), and scanning transmission electron energy loss spectroscopy (EELS). A Philips XL30 scanning electron microscope equipped with an Oxford Instruments energy-dispersive X-ray spectrometry (EDX) was used to characterise the microstructure and composition of the nanocomposite coating. Surface chemical analysis of the coating was carried out using a VG ESCALab X-ray Photoelectron Spectrometer. A Veeco CP-Research Scanning Probe Microscope (contact AFM mode) was used to measure the roughness of the deposited coatings. For TEM (conventional and high resolution) imaging, an FEI TECNAI F20 was used. EELS analysis was performed with a 100$\mathrm{keV}$ STEM instrument (VG HB 501) equipped with a field emission source and a parallel Gatan 666 EELS spectrometer.

\section{Results}

3.1. Differential Thermal Analysis (DTA). In AACVD process, the aerosol droplets of chemical precursor undergo evaporation and decomposition at elevated temperatures [19]. In order to study the intermediate reactions involved in the deposition, dried precursor powder was obtained by removing solvent from the precursor dispersion. Figure 1 shows DTA analysis of pure chromium nitrate nonahydrate and the dried precursor powder. As compared to the thermal behaviour of pure chromium nitrate nonahydrate, the main endothermic peak of the dried precursor powder shifts to $150-175^{\circ} \mathrm{C}$, indicating significant changes in the chemical structure. A small exothermic peak around $425^{\circ} \mathrm{C}$ can be found, which corresponds to the oxidation of IF-WS ${ }_{2}$ in the precursor powder. As reported [14], the oxidation of pure IF$\mathrm{WS}_{2}$ nanoparticles starts at $350^{\circ} \mathrm{C}$ and reaches its maximum at $400^{\circ} \mathrm{C}$. While the oxidation of IF-WS ${ }_{2}$ is significantly delayed in the DTA curve of dried precursor powder, indicating that IF-WS ${ }_{2}$ nanoparticles are covered and protected by intermediates of the precursor from oxidation at elevated temperatures.

3.2. FTIR Spectra. Figure 2 shows the FTIR spectra of pure chromium nitrate nonahydrate and the dried precursor powder. In both spectra, the broad peak at circa $3060 \mathrm{~cm}^{-1}$ can be assigned to nondissociated water and it is confirmed by the peak at $1630 \mathrm{~cm}^{-1}$. There are some new absorption peaks appearing in the FTIR spectrum of the dried precursor powder. The absorption bands centred at 1395, 1090, and $799 \mathrm{~cm}^{-1}$ could be assigned to $\mathrm{CH}_{3}$ bend, $\mathrm{C}-\mathrm{O}$ stretching, and $\mathrm{CH}_{2}$ rock vibration, respectively [20,21], which indicates that -OEt is introduced when chromium nitrate nonahydrate is dissolved in ethanol solvent. The new absorption band at $959 \mathrm{~cm}^{-1}$ can be assigned as antisymmetric O-Cr-O stret-ching vibration [22], while $892 \mathrm{~cm}^{-1}$ peak is associated with the symmetrical stretching mode of $\mathrm{Cr}-\mathrm{O}$ bond [23]. There is another extra band at $1550 \mathrm{~cm}^{-1}$, which may be due to the vibration of $\mathrm{O}-\mathrm{H}$ stretching in short $\mathrm{O}-\mathrm{H}-\mathrm{O}$ bonds of $\mathrm{Cr}(\mathrm{OH})_{3} \cdot 3 \mathrm{H}_{2} \mathrm{O}[24,25]$. Further details on the 


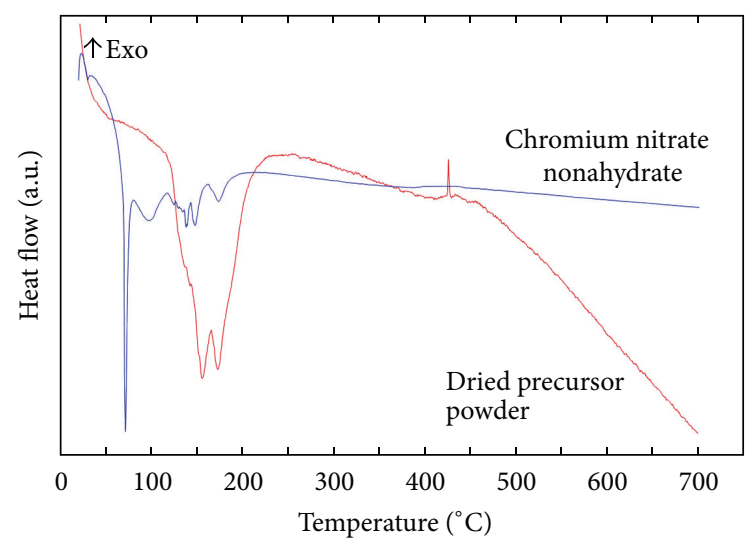

FIGURE 1: DTA analysis of chromium nitrate nonahydrate and the dried precursor powder.

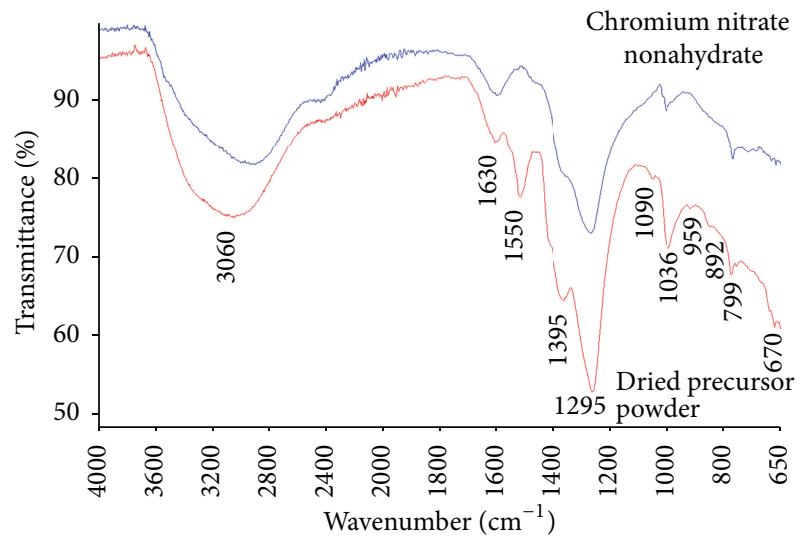

FIGURE 2: FTIR spectra of pure chromium nitrate nonahydrate and the dried precursor powder.

possible chemical structures and reactions will be discussed in Section 4.

3.3. EDX and XPS Analysis. Pure $\mathrm{Cr}_{2} \mathrm{O}_{3}$ coatings and IF-WS ${ }_{2} / \mathrm{Cr}_{2} \mathrm{O}_{3}$ nanocomposite coatings were produced via AACVD and subsequent annealing at $500^{\circ} \mathrm{C}$. EDX analysis of the nanocomposite coating is shown in Figure 3(a). The elements W and S can be clearly detected. Figure 3(b) presents XPS W(4f) line of nanocomposite coating, with the IF-WS 2 nanoparticles as reference. The presence of $\mathrm{W}$ could not be detected by XPS in the nanocomposite coating. Similarly, $\mathrm{S}$ element is also not detectable by XPS. As XPS has much smaller analysis depth than EDX, it reflects that the IF-WS ${ }_{2}$ nanoparticles have been fully covered by the matrix. Thus, there is no naked IF nanoparticle on the surface of the coating.

3.4. AFM Characterisation. The coatings were also characterised using AFM, to obtain further information on their surface morphology and roughness. As shown in Figure 4, the nanocomposite coating has a rough surface, with some peaks and valleys in microrange, while the pure $\mathrm{Cr}_{2} \mathrm{O}_{3}$ coating is smoother. There are some small grains appearing in the pure coating, several hundred nanometers in size. The average roughness $(\mathrm{Ra})$ of the two coatings in Figures 4(a) and 4 (b) are $16.9 \mathrm{~nm}$ and $62.6 \mathrm{~nm}$, respectively.

3.5. TEM and EELS Analysis. Figure 5(a) is an HREM image of IF nanoparticles incorporated in the nanocomposite coating. IF-WS ${ }_{2}$ nanoparticles are confirmed to be incorporated into the coatings by TEM. The hollow onion structure of IF$\mathrm{WS}_{2}$ can be clearly observed in Figure 5(a). Several spectrumlines were acquired across an IF-WS 2 particle (as shown in the inset of Figure 5(b)), in order to analyse the qualitative composition of the IF particle, matrix, and the interface [26]. Probe size is about $0.7 \mathrm{~nm}$, and the step was $3 \mathrm{~nm}$. Acquisition energy range was selected to analyse $\mathrm{O} \mathrm{K}$ edge, $\mathrm{S}$ and $\mathrm{Cr} \mathrm{L}$ edges, and $\mathrm{W}$ low energy edges $(\mathrm{O}$ and $\mathrm{N})$. Figure $5(\mathrm{~b})$ shows the intensity profiles for these edges. The resulting profiles clearly show the presence of $\mathrm{Cr}_{2} \mathrm{O}_{3}$ matrix on each side of the particle. It is noted that no $\mathrm{O}$ signal is detected in the IF-WS 2 nanoparticle, indicating that no oxidation of IF-WS has occurred in the deposition process and the subsequent heat treatment. Thus, the results suggest that the hollow onion structure and chemical composition of IF-WS 2 nanoparticles are preserved without apparent modification; however, the agglomeration of IF-WS ${ }_{2}$ has been observed.

\section{Discussion}

4.1. Chemical Reactions. In ethanol solution, nitrate group in $\mathrm{Cr}\left(\mathrm{NO}_{3}\right)_{3} \cdot 9 \mathrm{H}_{2} \mathrm{O}$ may be replaced by alkoxy group,

$$
\mathrm{Cr}\left(\mathrm{NO}_{3}\right)_{3} \cdot 9 \mathrm{H}_{2} \mathrm{O}+\mathrm{EtOH} \longrightarrow \mathrm{Cr}(\mathrm{OEt})_{3}+\mathrm{HNO}_{3}+\mathrm{H}_{2} \mathrm{O}
$$

The intermediate $\mathrm{Cr}(\mathrm{OEt})_{3}$ is unstable with the existence of water molecule, and $\mathrm{Cr}-\mathrm{OEt}$ bond would be hydrolysed to form $\mathrm{Cr}-\mathrm{OH}$ bond:

$$
\begin{array}{r}
\mathrm{Cr}(\mathrm{OEt})_{3}+\mathrm{H}_{2} \mathrm{O} \longrightarrow \mathrm{Cr}(\mathrm{OEt})_{x}(\mathrm{OH})_{(3-x)}+\mathrm{EtOH} \\
(x=0,1,2) \\
\mathrm{Cr}(\mathrm{OEt})_{x}(\mathrm{OH})_{(3-x)}+x \mathrm{H}_{2} \mathrm{O} \longrightarrow \mathrm{Cr}(\mathrm{OH})_{3}+x \mathrm{EtOH} \\
(x=1,2)
\end{array}
$$

Then $\mathrm{Cr}(\mathrm{OH})_{3}$ may absorb more water to form $\mathrm{Cr}(\mathrm{OH})_{3}$. $3 \mathrm{H}_{2} \mathrm{O}$. In Figure 2, the FTIR spectrum proofs the presence of $\mathrm{Cr}(\mathrm{OH})_{3} \cdot 3 \mathrm{H}_{2} \mathrm{O}$ in the dried precursor powder. As the nitrate structure is still observed from FTIR, it is suggested that the dried precursor powder is a mixture of nitrate and hydroxide, and only part of nitrate has been converted in reaction (1).

At elevated temperature, chromium nitrate would directly decompose to $\mathrm{Cr}_{2} \mathrm{O}_{3}$ [27], and chromium hydroxide can form $\mathrm{Cr}_{2} \mathrm{O}_{3}$ via reaction (3) [28]:

$$
\mathrm{Cr}(\mathrm{OH})_{3} \cdot 3 \mathrm{H}_{2} \mathrm{O} \longrightarrow \mathrm{Cr}_{2} \mathrm{O}_{3}+\mathrm{H}_{2} \mathrm{O}
$$

In the real AACVD process, the chemical reactions and intermediates will be more complicated than the interpretation for the dried precursor powder. But it is suggested that 


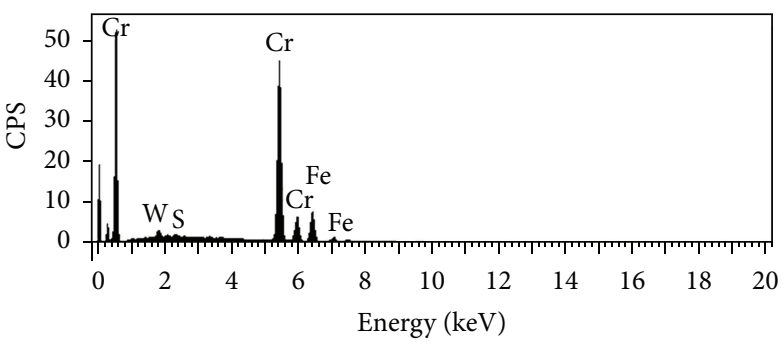

(a)

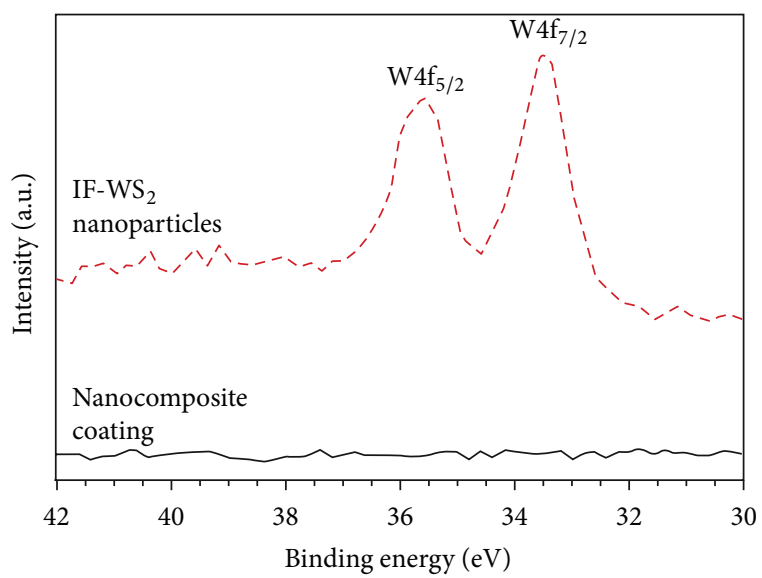

(b)

FIGURE 3: Analysis of the IF-WS ${ }_{2} / \mathrm{Cr}_{2} \mathrm{O}_{3}$ nanocomposite coating. (a) EDX of nanocomposite coating and (b) XPS W(4f) line of IF-WS nanoparticle and nanocomposite coating.

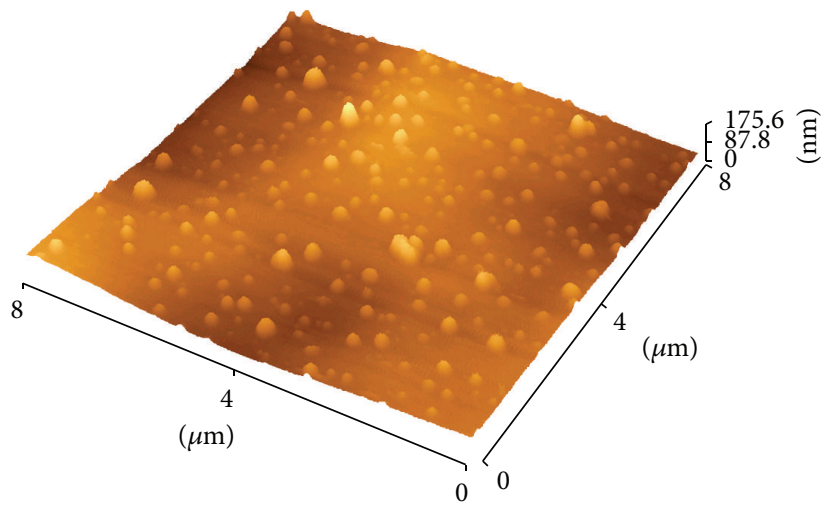

(a)

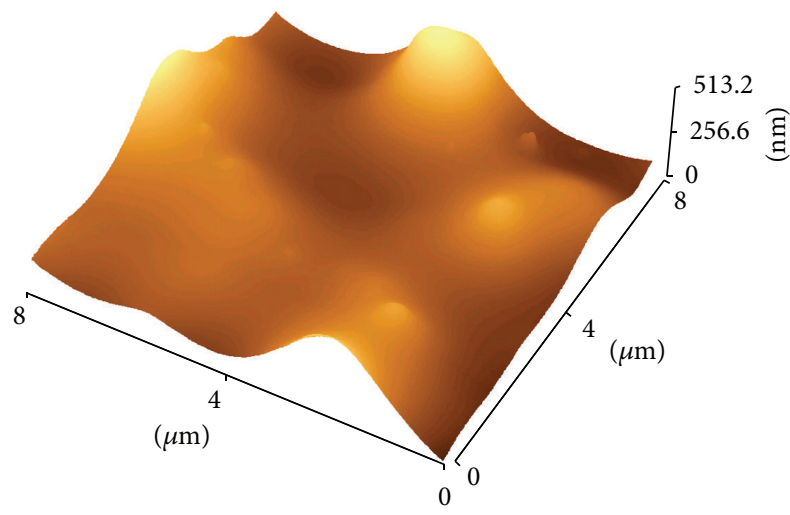

(b)

FIGURE 4: AFM images of the pure $\mathrm{Cr}_{2} \mathrm{O}_{3}$ (a) and the IF-WS ${ }_{2} / \mathrm{Cr}_{2} \mathrm{O}_{3}$ nanocomposite coatings (b).

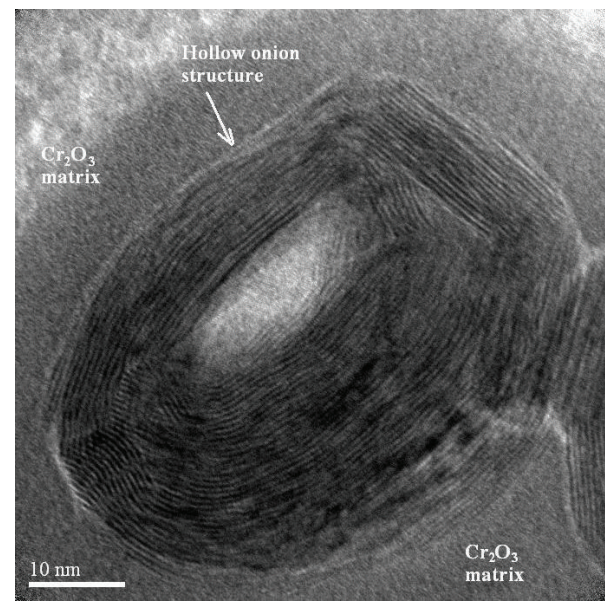

(a)

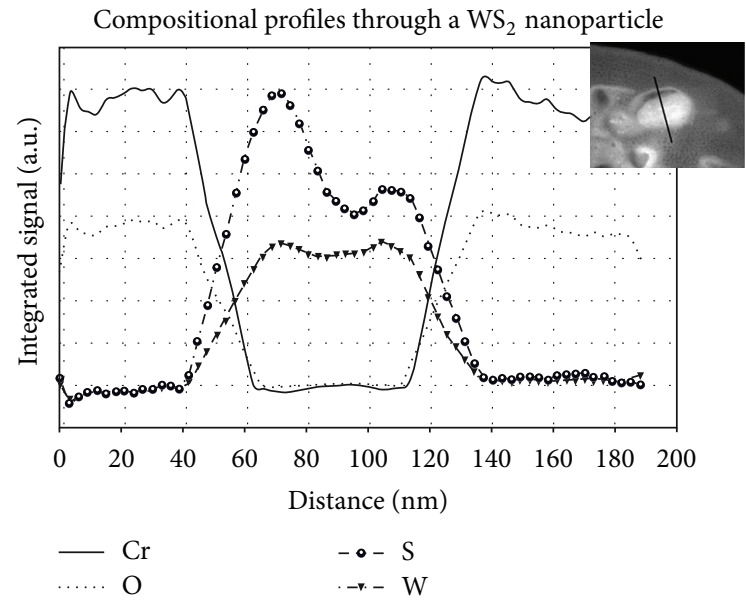

(b)

FIGURE 5: TEM imaging and EELS analysis of the IF-WS ${ }_{2} / \mathrm{Cr}_{2} \mathrm{O}_{3}$ nanocomposite coatings. (a) HREM image of an IF-WS 2 particle showing typical layered structure formed by S-W-S sheets. (b) Qualitative compositional profiles after PCA analysis across an IFLM particle showing that no interdiffusion or oxidation of the particle takes place. The integrated signal has not been divided by the cross-section; the black line in the inset has the length of $130 \mathrm{~nm}$. 


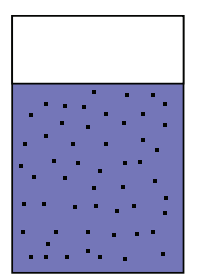

(a)

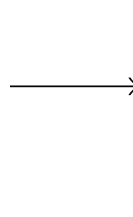

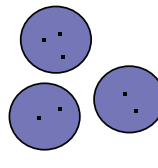

b)

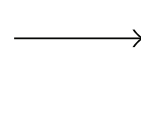

(c)

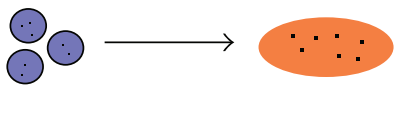

(c)

(d)

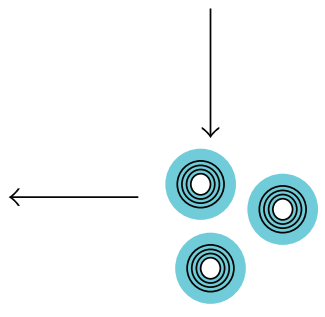

(e)

(f)

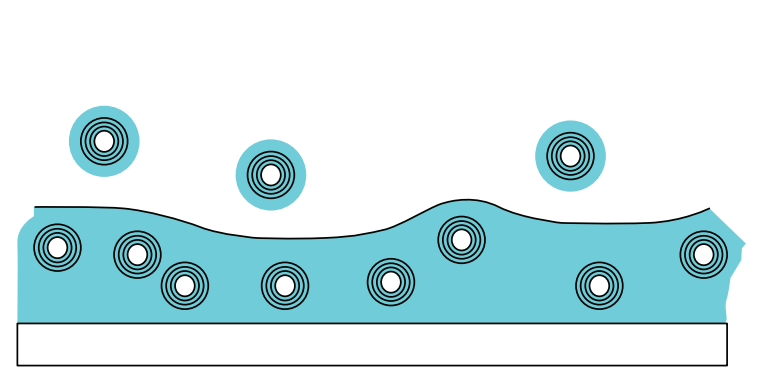

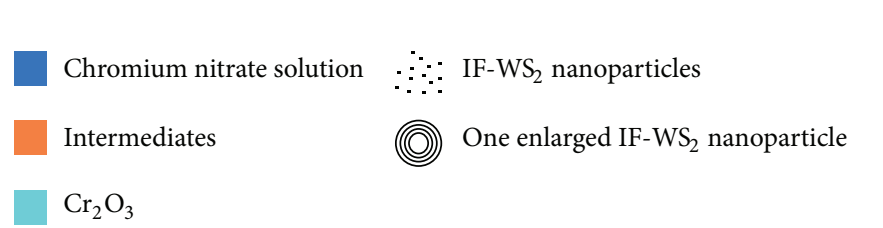

FIGURE 6: Deposition of nanocomposite coating using AACVD. (a) Formation of precursor dispersion consisting of chromium nitrate and IF$\mathrm{WS}_{2}$ nanoparticles, (b) atomization of precursor dispersion, (c) evaporation of solvent, (d) decomposition and chemical reactions of precursor intermediates in gas phase, (e) nucleation and growth on IF nanoparticle surface, and (f) deposition of IF-WS $\mathrm{W}_{2} / \mathrm{Cr}_{2} \mathrm{O}_{3}$ on the substrate surface.

alkoxy and hydroxide structure are involved in the reactions. At elevated temperature, it is a procedure of releasing Ncontaining groups and water, which corresponds to the main endothermic peak at $150 \sim 175^{\circ} \mathrm{C}$ in Figure 1.

4.2. Deposition Mechanism. To synthesize IF-WS $/ \mathrm{Cr}_{2} \mathrm{O}_{3}$ nanocomposite coatings, the precursor dispersion consisting of IF nanoparticles was atomized to produce fine aerosol droplets. These aerosol droplets were subsequently directed towards a heated zone where they underwent evaporation, decomposition, chemical reactions, and deposition. In this process, IF nanoparticles were incorporated into the coating via "codeposition." There are some studies on codeposition of particles via homogeneous nucleation using CVD process [29-32]. However, in the current study, the IF nanoparticles were obtained separately, instead of being formed in situ simultaneously with the matrix, which could provide independent control for both nanoparticles and matrix materials. IF nanoparticles might induce nucleation and growth of matrix on their surface in gas phase, prior to the deposition occurring on the substrate surface. The deposition mechanism of AACVD with IF nanoparticles is proposed in Figure 6 and described as follows.

(a) Formation of precursor dispersion consisting of chromium nitrate and IF-WS ${ }_{2}$ nanoparticles: chromium nitrate is dissolved into ethanol-based solvent to form homogeneous solution, and IF-WS ${ }_{2}$ nanoparticles are distributed in the solution uniformly to obtain the desired dispersion.

(b) Atomization of precursor dispersion: the liquid dispersion is atomized to form fine aerosol droplets with diameter ranging from 1 to 10 microns. The size of the IF nanoparticles is circa $80-220 \mathrm{~nm}$, so one droplet of dispersion, for example, may contain one or more nanoparticles. The aerosol droplets are delivered to the reaction area by carrier gas, together with the IF nanoparticles.

(c) Evaporation of solvent: when the aerosol droplets are being transported, they will undergo substantial evaporation, especially with increased environmental temperature. The small size and the large specific surface area of these droplets will accelerate the evaporation of solvent. The evaporation can cause rapid evaporative cooling effect and lead to decrease of surface temperature of droplets until heat transfer between the droplets and the environmental reaches a temporal balance [33]. Therefore, the fine aerosol droplets make it possible to achieve rapid removal of solvent when they are approaching the heated substrate.

(d) Decomposition and chemical reactions of precursor intermediates in gas phase: the decomposition and 
chemical reactions of the precursor occur rapidly at the elevated temperatures. Some intermediates of precursor start to form in gas phase. From the TEM analysis, IF-WS ${ }_{2}$ nanoparticles remain stable in the deposition. IF nanoparticles are always transported with the chemical precursor, when they are surrounded by the precursor intermediates, their surface can adsorb some intermediates or active species due to the high specific surface area.

(e) Nucleation and growth on the IF nanoparticle surface: before reaching the substrate, IF nanoparticles play an important role as the "nucleation seeds" of $\mathrm{Cr}_{2} \mathrm{O}_{3}$ via heterogeneous reactions. Nucleation takes place from the adsorbed intermediates or active species on the surface of IF nanoparticles, where a thin layer of $\mathrm{Cr}_{2} \mathrm{O}_{3}$ is formed. Then a kind of spherical particles with $\mathrm{Cr}_{2} \mathrm{O}_{3}$ shell and IF core would be obtained. Via continuous heterogeneous reaction, these spherical particles grow bigger and bigger. Then all IF nanoparticles are covered by the $\mathrm{Cr}_{2} \mathrm{O}_{3}$ shell before they reach the substrate surface. The $\mathrm{Cr}_{2} \mathrm{O}_{3}$ shell can protect the IF nanoparticles from oxidation and other chemical reactions, so the unique hollow onion structure of IF can be preserved as shown in Figure 5(a). However, in the AACVD of pure $\mathrm{Cr}_{2} \mathrm{O}_{3}$ coating, there is no extra surface for heterogeneous reactions in the gas phase. Heterogeneous nucleation only happens on the surface of substrate. Thus, it is suggested that heterogeneous nucleation on the IF$\mathrm{WS}_{2}$ surface is one of the key features for the synthesis of nanocomposite coatings using AACVD process.

(f) $\mathrm{Cr}_{2} \mathrm{O}_{3}$ can also directly deposit onto the substrate surface from the gas-phase species via heterogeneous reactions, similar to that of pure $\mathrm{Cr}_{2} \mathrm{O}_{3}$ coating in AACVD process, which is the major route for the formation of $\mathrm{Cr}_{2} \mathrm{O}_{3}$ matrix. Simultaneously, the IF-WS nanoparticles with the $\mathrm{Cr}_{2} \mathrm{O}_{3}$ shells are delivered and deposited onto the substrate surface. The $\mathrm{Cr}_{2} \mathrm{O}_{3}$ shells outside the IF-WS $\mathrm{W}_{2}$ nanoparticles can be merged with the major $\mathrm{Cr}_{2} \mathrm{O}_{3}$ coating matrix in the subsequent deposition. As the deposition temperature is no more than $350^{\circ} \mathrm{C}$, no oxidation of $\mathrm{WS}_{2}$ occurs, and the IF$\mathrm{WS}_{2}$ nanoparticles remain stable.

In the deposition of pure $\mathrm{Cr}_{2} \mathrm{O}_{3}$ coating in AACVD, the heterogeneous nucleation of $\mathrm{Cr}_{2} \mathrm{O}_{3}$ only takes place at the substrate surface. Therefore, some small grain features on the coating surface can be observed from AFM image, and the coating is much smoother than that incorporated with IF nanoparticles, as seen in Figure 4. In the synthesis of nanocomposite coating, the heterogeneous nucleation of $\mathrm{Cr}_{2} \mathrm{O}_{3}$ also occurs on IF nanoparticles in the gas phase, so that the IF nanoparticles become bigger and bigger before they reach the substrate. After they have deposited onto the substrate and merge with the coating matrix, bigger peaks appear which significantly increases the surface roughness of the coatings. Thus, a much rougher surface is formed. As all IF nanoparticles are fully covered by $\mathrm{Cr}_{2} \mathrm{O}_{3}$ shell before they reach the substrate surface, no naked IF nanoparticle can be detected by XPS on the surface of the nanocomposite coating.

In summary, as the nanoparticles have high specific surface area and they have close contact with the chemical reactants during the transport period, the heterogeneous reaction starts on the nanoparticles surface. It is suggested that the heterogeneous reaction on the surface of IF nanoparticles, before they reach the substrate, is the key point in the AACVD of nanocomposite coatings. The heterogeneous reaction would lead to the formation of a shelled layer on the nanoparticle surface, which greatly influences the microstructure and surface roughness of the coatings.

\subsection{Agglomeration of IF Nanoparticles inside the Nanocom-} posite Coatings. Agglomeration is a general tendency of nanoscale materials. It is normally believed that nonagglomerated or less-agglomerated nanoscale materials could be beneficial to their unique properties. Ideally, it is desirable to have uniform and nonagglomerated distribution of nanoparticles inside the coating matrix. However, it is found that the agglomeration of IF nanoparticles occurred in the IF$\mathrm{WS}_{2} / \mathrm{Cr}_{2} \mathrm{O}_{3}$ nanocomposite coatings [18]. Thus, there is a need to minimize the agglomeration of IF nanoparticles inside the nanocomposite coating.

There are several possible sources and reasons of IF agglomeration in the final nanocomposite coatings produced by AACVD, as follows.

(i) The supplied nanoparticles: if heavy agglomeration exists in the supplied nanoparticles, proper separation methods have to be applied to break up the agglomerates. Otherwise, the agglomeration will remain in the final nanocomposite coating. Therefore, less agglomerated nanoparticles would be favourable.

(ii) Preparation of precursor dispersion consisting of nanoparticles: IF nanoparticles are required to be well dispersed in the precursor solution. Ultrasonic bath or other methods can be used to break up the agglomerates and obtain stable dispersion. Surfactant might be used in this stage to improve the stability of the dispersion.

(iii) Atomization of precursor dispersion: in the atomization stage, nanoparticles will be loaded and carried by the aerosol droplets. If the droplet is big, it would carry more nanoparticles, which may have more chance for agglomeration in this droplet. Therefore, smaller size droplet is preferred. The same requirement can also be applied to the distribution of the droplets size. Thus, fine and uniform aerosol droplets are required for less-agglomeration in the AACVD process.

(iv) Evaporation of solvent in the aerosol droplets: as discussed previously, evaporation of solvent takes place in the droplets transport period. If one droplet contains more nanoparticles, agglomeration of these nanoparticles may occur when the droplet shrinks, especially when all solvent has been evaporated from the droplet. It indicates that using finer aerosol 
droplets or lowering the nanoparticle concentration in the dispersion may be helpful to reduce the possible agglomeration in this stage.

(v) Heterogeneous reactions on the surface of IF nanoparticles during their transport period: before IF nanoparticles reaches the substrates, substantial heterogeneous reactions would occur on the surface of IF nanoparticles and form a layer of $\mathrm{Cr}_{2} \mathrm{O}_{3}$. The $\mathrm{Cr}_{2} \mathrm{O}_{3}$ may act as connective materials between nanoparticles. This kind of agglomeration may be minimized by reducing the earlier heterogeneous reactions, via optimizing the processing parameters, such as deposition temperature and gas flow rate.

Therefore, it is suggested that the agglomeration of IF nanoparticles inside the nanocomposite coating is a combination of the physical and chemical properties of the nanoparticles and all the processing steps. Various measures can be applied to minimize the possible IF agglomeration at the different steps of the AACVD process. The results and conclusions would also be helpful for the fabrication of nanocomposite coatings using other processing techniques.

\section{Conclusions}

IF-WS 2 nanoparticles have been incorporated into $\mathrm{Cr}_{2} \mathrm{O}_{3}$ coating matrix to form nanocomposite coatings using AACVD. Hollow onion structure and chemical composition of IF-WS $\mathrm{S}_{2}$ nanoparticles are preserved inside the matrix. All IF nanoparticles are fully covered by the coating matrix and no naked IF nanoparticle can be detected. Individual IF nanoparticle in the coating can be clearly characterised by TEM analysis, but the agglomeration of the IF nanoparticles also exists. As compared to pure $\mathrm{Cr}_{2} \mathrm{O}_{3}$ coatings, the nanocomposite coatings have a much rougher surface.

The chemical reactions and intermediates in the AACVD process could be complex. From the thermal decomposition of the dried precursor powder, it is suggested that alkoxy and hydroxide structures are involved in the reactions.

A deposition mechanism has been proposed to discuss the codeposition of nanocomposite coating using AACVD. The heterogeneous reaction on the surface of IF nanoparticles, before they reach the substrate, is the key point in AACVD of nanocomposite coatings. The heterogeneous reaction would lead to the formation of a $\mathrm{Cr}_{2} \mathrm{O}_{3}$ shell on the nanoparticles surface, which greatly influences the microstructure and surface roughness of the coatings.

The agglomeration of IF nanoparticles inside the nanocomposite coatings might be attributed to the as-received nanoparticles and AACVD process. Various measures have been discussed for minimizing the possible IF agglomeration at different steps in the process. The results and conclusions would also be helpful for the fabrication of nanocomposite coatings using other processing techniques.

\section{Acknowledgments}

The authors would like to thank the European Union for financial support under the EU-Sixth Framework
FOREMOST project (Contract FP6-515840). They also would like to thank Mr. Martin Roe for performing XPS surface analysis and NanoMaterials Ltd. for kindly supplying IF-WS ${ }_{2}$ nanoparticles for this research.

\section{References}

[1] P. Dutta and S. Gupta, Understanding of Nano Science and Technology, Global Vision Publishing House, New Delhi, India, 2006.

[2] J. Kong, N. R. Franklin, C. Zhou et al., "Nanotube molecular wires as chemical sensors," Science, vol. 287, no. 5453, pp. 622$625,2000$.

[3] D. B. Kittelson, "Engines and nanoparticles: a review," Journal of Aerosol Science, vol. 29, no. 5-6, pp. 575-588, 1998.

[4] R. H. Baughman, A. A. Zakhidov, and W. A. De Heer, "Carbon nanotubes-the route toward applications," Science, vol. 297, no. 5582, pp. 787-792, 2002.

[5] J. Pérez-Juste, I. Pastoriza-Santos, L. M. Liz-Marzán, and P. Mulvaney, "Gold nanorods: synthesis, characterization and applications," Coordination Chemistry Reviews, vol. 249, pp. 1870-1901, 2005.

[6] H. G. Yang, G. Liu, S. Z. Qiao et al., "Solvothermal synthesis and photoreactivity of anatase $\mathrm{TiO}_{2}$ nanosheets with dominant 001 facets," Journal of the American Chemical Society, vol. 131, no. 11, pp. 4078-4083, 2009.

[7] Z. L. Wang, "Functional oxide nanobelts: materials, properties and potential applications in nanosystems and biotechnology," Annual Review of Physical Chemistry, vol. 55, pp. 159-196, 2004.

[8] G. Kickelbick, "Concepts for the incorporation of inorganic building blocks into organic polymers on a nanoscale," Progress in Polymer Science, vol. 28, pp. 83-114, 2003.

[9] L. Rapoport, N. Fleischer, and R. Tenne, "Applications of $\mathrm{WS}_{2}$ $\left(\mathrm{MoS}_{2}\right)$ inorganic nanotubes and fullerene-like nanoparticles for solid lubrication and for structural nanocomposites," Journal of Materials Chemistry, vol. 15, pp. 1782-1788, 2005.

[10] C. Sanchez, B. Julián, P. Belleville, and M. Popall, "Applications of hybrid organic-inorganic nanocomposites," Journal of Materials Chemistry, vol. 15, no. 35-36, pp. 3559-3592, 2005.

[11] D. R. Paul and L. M. Robeson, "Polymer nanotechnology: nanocomposites," Polymer, vol. 49, no. 15, pp. 3187-3204, 2008.

[12] L. Rapoport, Y. Bilik, Y. Feldman, M. Homyonfer, S. R. Cohen, and R. Tenne, "Hollow nanoparticles of $\mathrm{WS}_{2}$ as potential solidstate lubricants," Nature, vol. 387, no. 6635, pp. 791-793, 1997.

[13] W. X. Chen, J. P. Tu, Z. D. Xu et al., "Wear and friction of Ni$\mathrm{P}$ electroless composite coating including inorganic fullerene$\mathrm{WS}_{2}$ nanoparticles," Advanced Engineering Materials, vol. 4, pp. 686-690, 2002.

[14] X. H. Hou, C. X. Shan, and K. L. Choy, "Microstructures and tribological properties of PEEK-based nanocomposite coatings incorporating inorganic fullerene-like nanoparticles," Surface and Coatings Technology, vol. 202, pp. 2287-2291, 2008.

[15] X. H. Hou, P. T. Deem, and K. L. Choy, "Hydrophobicity study of polytetrafluoroethylene nanocomposite films," Thin Solid Films, vol. 520, pp. 4916-4920, 2012.

[16] R. G. Palgrave and I. P. Parkin, "Aerosol assisted chemical vapor deposition using nanoparticle precursors: a route to nanocomposite thin films," Journal of the American Chemical Society, vol. 128, no. 5, pp. 1587-1597, 2006. 
[17] A. D. Ross and K. K. Gleason, "The CVD of nanocomposites fabricated via ultrasonic atomization," Chemical Vapor Deposition, vol. 12, pp. 225-230, 2006.

[18] X. Hou and K. L. Choy, "Synthesis of $\mathrm{Cr}_{2} \mathrm{O}_{3}$-based nanocomposite coatings with incorporation of inorganic fullerene-like nanoparticles," Thin Solid Films, vol. 516, no. 23, pp. 8620-8624, 2008.

[19] X. H. Hou and K. L. Choy, "Processing and applications of aerosol-assisted chemical vapor deposition," Chemical Vapor Deposition, vol. 12, pp. 583-596, 2006.

[20] R. A. Qyquist, Interpreting Infrared, Raman and Nuclear Magnetic Resonance Spectra, vol. 1, Academic press, London, UK, 2001.

[21] J. M. Chalmers and P. R. Griffiths, Handbook of Vibrational Spectroscopy, vol. 3, John Wiley \& Sons, Chichester, UK, 2001.

[22] M. F. Zhou and L. Andrews, "Infrared spectra and density functional calculations of the $\mathrm{CrO}_{2}{ }^{-}, \mathrm{MoO}_{2}{ }^{-}$, and $\mathrm{WO}_{2}{ }^{-}$ molecular anions in solid neon," Journal of Chemical Physics, vol. 111, p. 4230, 1999.

[23] K. H. Xiang, R. Pandey, J. M. Recio, E. Francisco, and J. M. Newsam, "A theoretical study of the cluster vibrations in $\mathrm{Cr}_{2} \mathrm{O}_{2}$, $\mathrm{Cr}_{2} \mathrm{O}_{3}$, and $\mathrm{Cr}_{2} \mathrm{O}_{4}$," Journal of Physical Chemistry A, vol. 104, no. 5, pp. 990-994, 2000.

[24] M. Schraml-Marth, A. Wokaun, H. E. Curry-Hyde, and A. Baiker, "Surface structure of crystalline and amorphous chromia catalysts for the selective catalytic reduction of nitric oxide II. Diffuse reflectance FTIR study of thermal treatment and oxygen adsorption," Journal of Catalysis, vol. 133, no. 2, pp. 415430, 1992.

[25] K. K. Singh, P. R. Sarode, and P. Ganguly, "Evolution of $\alpha-\mathrm{Cr}_{2} \mathrm{O}_{2}$ from hydrous chromium oxides: magnetic susceptibility and extended $X$-ray absorption fine structure studies," Journal of the Chemical Society, Dalton Transactions, pp. 1895-1899, 1983.

[26] M. Watanabe, E. Okunishi, and K. Ishizuka, "Analysis of spectrum-imaging datasets in atomic-resolution electron microscopy," Microscopy and Analysis, vol. 23, pp. 5-7, 2009.

[27] M. García, M. Jergel, A. Conde-Gallardo, C. Falcony, and G. Plesch, "Optical properties of $\mathrm{Co}$ and $\mathrm{Co}-\mathrm{Fe}-\mathrm{Cr}$ thin films deposited from an aerosol on glass substrates," Materials Chemistry and Physics, vol. 56, no. 1, pp. 21-26, 1998.

[28] Y. L. Bai, H. B. Xu, Y. Zhang, and Z. H. Li, "Reductive conversion of hexavalent chromium in the preparation of ultra-fine chromia powder," Journal of Physics and Chemistry of Solids, vol. 67, pp. 2589-2595, 2006.

[29] R. H. Hurt and M. D. Allendorf, "Model of particle-vapor codeposition with application to ceramic materials synthesis," AIChE Journal, vol. 37, no. 10, pp. 1485-1496, 1991.

[30] A. Gurav, T. Kodas, T. Pluym, and Y. Xiong, "Aerosol processing of materials," Aerosol Science and Technology, vol. 19, no. 4, pp. 411-452, 1993.

[31] Y. Wang, M. Sasaki, and T. Hirai, "Thermal properties of chemical vapour-deposition SiC-C nanocomposites," Journal of Materials Science, vol. 26, pp. 5495-5501, 1991.

[32] U. Backman, A. Auvinen, and J. K. Jokiniemi, "Deposition of nanostructured titania films by particle-assisted MOCVD," Surface and Coatings Technology, vol. 192, no. 1, pp. 81-87, 2005.

[33] R. J. Hopkins and J. P. Reid, "Evaporation of ethanol/water droplets: examining the temporal evolution of droplet size, composition and temperature," Journal of Physical Chemistry A, vol. 109, pp. 7923-7931, 2005. 

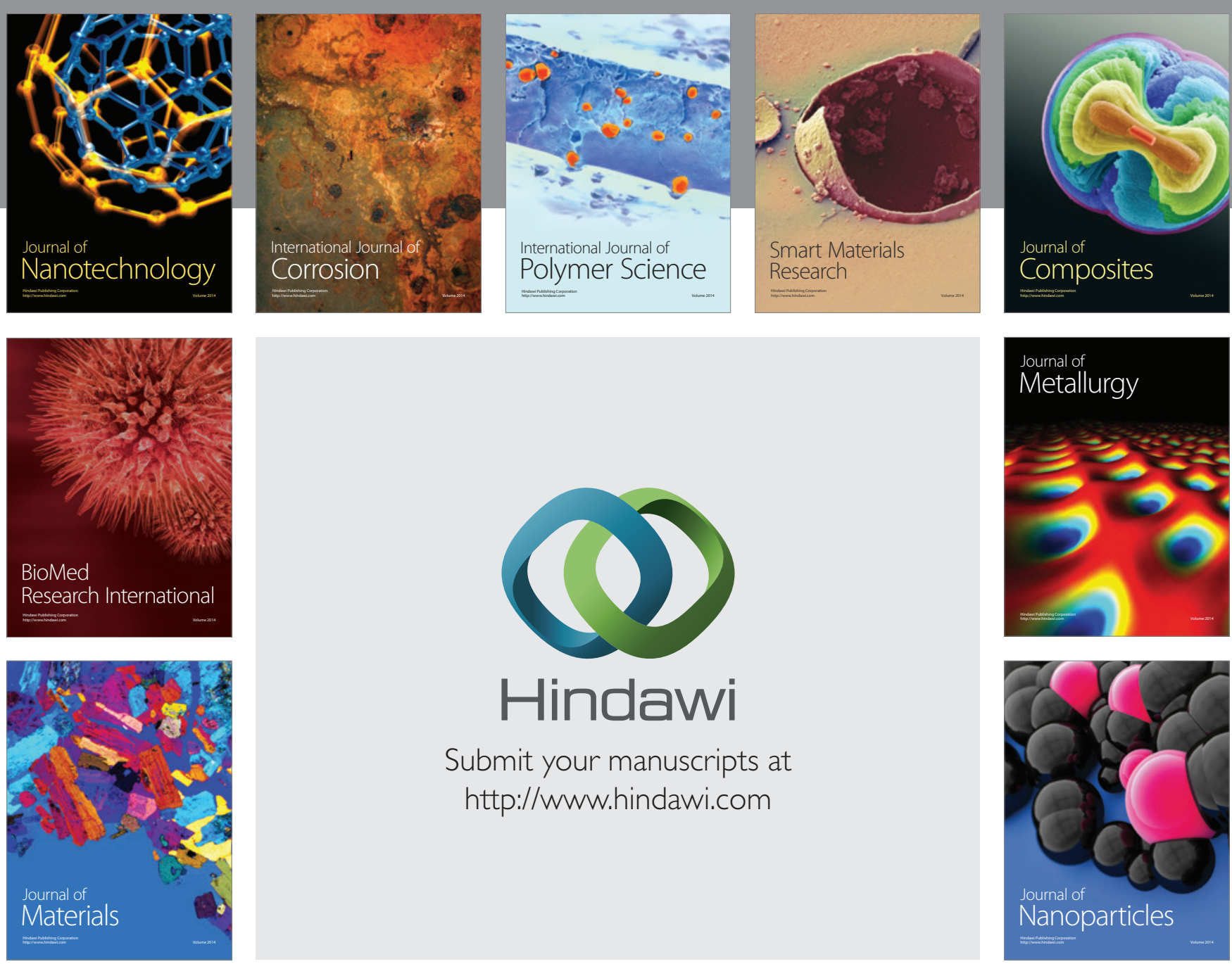

Submit your manuscripts at http://www.hindawi.com
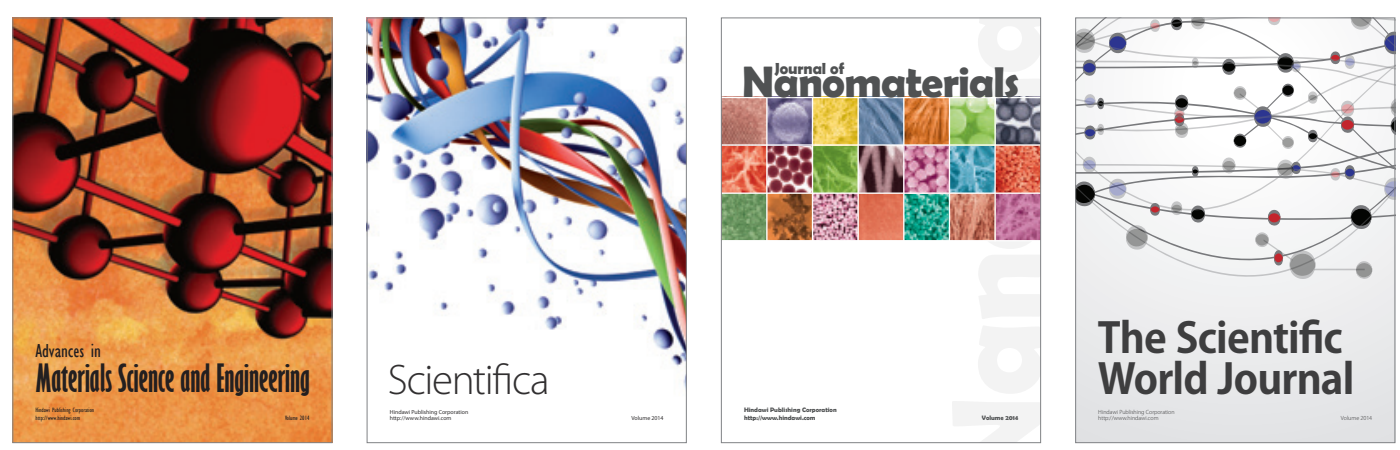

\section{The Scientific World Journal}
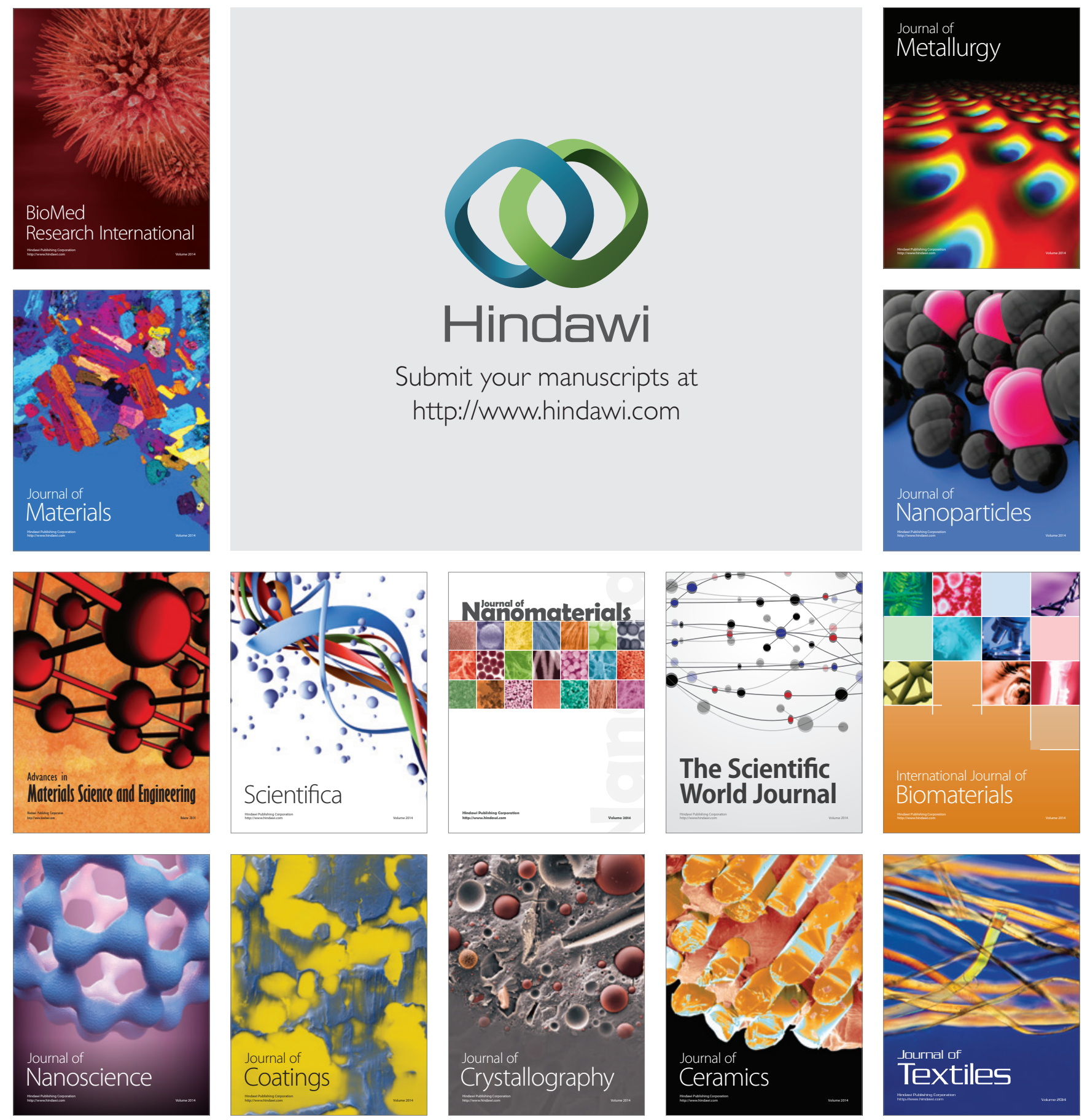